\title{
What role for recombinant human TSH in the treatment of metastatic thyroid cancer?
}

\author{
Paolo Zanotti-Fregonara $\cdot$ Elif Hindié • \\ Marie Elisabeth Toubert • Domenico Rubello
}

Published online: 20 January 2009

(C) Springer-Verlag 2009

The introduction into clinical practice of recombinant human thyroid-stimulating hormone (rhTSH) has marked a turning point in the management of patients with differentiated thyroid cancer. RhTSH offers a safe and reliable alternative to thyroid hormone withdrawal by avoiding both the clinical consequences of hypothyroidism, with a positive impact on quality of life and work productivity, and the potential risk of cancer growth due to a long-lasting endogenous TSH stimulation.

In the follow-up of thyroid cancer patients, rhTSH stimulated thyroglobulin is now routinely proposed as it has been shown to be as sensitive as endogenously stimulated thyroglobulin for the detection of residual and metastatic cancer [1].

More recently, the use of rhTSH has been approved for the preparation of adult low-risk patients for postsurgical radioiodine ablation of thyroid remnants with $3.7 \mathrm{GBq}^{131} \mathrm{I}$ [2]. Although the activity necessary to achieve a comparable rate of ablation is probably higher than that required under hypothyroidism [3, 4], the use of rhTSH is associated with a lower whole-body radiation exposure [5] and allows a shorter hospitalization length, which partially compensates for its cost [6].

\section{P. Zanotti-Fregonara}

DSV/I(2)BM/SHFJ, Commissariat à l'Energie Atomique,

Orsay, France

E. Hindié $\cdot$ M. E. Toubert

Department of Nuclear Medicine, Saint-Louis Hospital,

Assistance Publique-Hôpitaux de Paris,

Paris, France

D. Rubello $(\triangle)$

Department of Nuclear Medicine,

PET Centre, 'S. Maria della Misericordia' Hospital,

Viale Tre Martiri,

140 Rovigo, Italy

e-mail: domenico.rubello@libero.it
The use of rhTSH in the treatment of metastatic thyroid cancer is much more controversial. Although rhTSH has not been formally approved so far for this indication, it has been used off-label since the 1990s to treat patients in which thyroid hormones could not be stopped [7]. This includes patients unable to raise an adequate endogenous TSH response, either because of hypopituitarism or continued production of thyroxine by a thyroid remnant or metastatic tumour, and patients in poor condition due to advanced disease. The results obtained in some patients are encouraging.

One may raise the question whether a wider use of rhTSH can be advovated in the therapeutic setting. In our opinion, both clinical and biological data from the literature argue against a more liberal use of rhTSH for the therapy of metastatic thyroid cancer. First, tumour cells of thyroid cancer have a reduced expression of most thyroid-specific genes, including the TSH receptor and the $\mathrm{Na}^{+} / I^{-}$symporter (NIS) gene [8]. Although the standard two injections protocol of rhTSH provides a high plasma TSH peak, roughly in the range 100-150 mIU/L $24 \mathrm{~h}$ after the second injection [9], the concentration increase is short-lived [10]. In order to improve the number of NIS and TSH receptors, and thus enhance the iodine-trapping ability of the cells, a high and prolonged period of TSH stimulation elevation is desirable [11]. Indeed, a ${ }^{131} \mathrm{I}$ whole-body scan under hypothyroidism is more sensitive than the same scan after rhTSH administration [12]. It should be remembered that a posttherapeutic scan of good quality is an invaluable tool to discover unsuspected metastases and to assess the efficacy of repeated ${ }^{131} \mathrm{I}$ treatment in metastatic patients [13].

Second, published experience shows that rhTSH stimulates the uptake of radioiodine in metastatic lesions [7]. However, prospective randomized studies comparing the relative efficacy of rhTSH-aided metastatic cancer treat- 
ment to treatment under hypothyroidism are lacking. Retrospective analyses are not helpful given the heterogeneity of patients with metastatic thyroid cancer and the fact that rhTSH is often used on a compassionate basis in frailer patients, or in patients with more advanced disease. However, the few case reports published so far, in which direct intrapatient comparison is available, suggest that stimulation by rhTSH may be less effective than hormone withdrawal in concentrating radioiodine into metastatic lesions $[14,15]$. Finally, biokinetic data show that the radiation dose delivered to neoplastic lesions after rhTSH stimulation is lower than that delivered following hormone withdrawal [16]. In patients stimulated with rhTSH, the radioiodine uptake and the cumulative activity in metastatic tissue were lower than during hypothyroidism, particularly in the case of bone metastases.

Moreover, one should not forget that rhTSH administration in metastatic patients is not completely risk-free, as it may be associated with sudden swelling of metastases in closed spaces of the body, such as the brain or vertebrae [17].

The use of rhTSH is associated with a lower whole-body dosimetry as compared to the hypothyroid state [5], mainly because of a faster clearance of radioactivity from the blood of euthyroid patients. This is an important advantage especially when managing young patients with a limited extent of disease, who have an overall good prognosis and a long disease-free survival. However, patients with distant metastases are a subgroup with markedly reduced survival who often die from their disease [18]. Radioiodine is the most effective therapeutic tool in patients with iodine-avid metastatic disease [18]. A low statistical risk of secondary leukaemia appears only after high cumulative doses of ${ }^{131} \mathrm{I}$ [19] and the link between ${ }^{131}$ I therapy and secondary solid cancers has not yet been clearly established $[19,20]$. The risk of late secondary malignancies should not prevent us from treating an actual cancer with a poor prognosis.

In total, currently available biological and clinical data, although somewhat limited, argue against the routine use of rhTSH for the treatment metastatic thyroid cancer. RhTSH should be reserved for the treatment of those patients in whom hormone withdrawal is medically contraindicated. In patients with distant metastases, whole-body ${ }^{131}$ I dosimetry should be a relatively minor concern, as these patients often die from the disease, and aggressive therapy with ${ }^{131} \mathrm{I}$ often constitutes their only chance of survival.

\section{References}

1. Eustatia-Rutten CF, Smit JW, Romijn JA, van der Kleij-Corssmit EP, Pereira AM, Stokkel MP, et al. Diagnostic value of serum thyroglobulin measurements in the follow-up of differentiated thyroid carcinoma, a structured meta-analysis. Clin Endocrinol (Oxf) 2004;61:61-74. doi:10.1111/j.1365-2265.2004.02060.x.
2. Haugen BR, Cooper DS, Emerson CH, Luster M, Maciel RM, Biscolla RP, et al. Expanding indications for recombinant human TSH in thyroid cancer. Thyroid 2008;18:687-94. doi:10.1089/ thy.2008.0162.

3. Pacini F, Molinaro E, Castagna MG, Lippi F, Ceccarelli C, Agate $\mathrm{L}$, et al. Ablation of thyroid residues with $30 \mathrm{mCi}$ (131)I: a comparison in thyroid cancer patients prepared with recombinant human TSH or thyroid hormone withdrawal. J Clin Endocrinol Metab 2002;87:4063-8. doi:10.1210/jc.2001-011918.

4. Pacini F, Ladenson PW, Schlumberger M, Driedger A, Luster M, Kloos RT, et al. Radioiodine ablation of thyroid remnants after preparation with recombinant human thyrotropin in differentiated thyroid carcinoma: results of an international, randomized, controlled study. J Clin Endocrinol Metab 2006;91:926-32. doi:10.1210/jc.2005-1651.

5. Luster M, Sherman SI, Skarulis MC, Reynolds JR, Lassmann M, Hänscheid $\mathrm{H}$, et al. Comparison of radioiodine biokinetics following the administration of recombinant human thyroid stimulating hormone and after thyroid hormone withdrawal in thyroid carcinoma. Eur J Nucl Med Mol Imaging 2003;30:13717. doi:10.1007/s00259-003-1230-1.

6. Borget I, Remy H, Chevalier J, Ricard M, Allyn M, Schlumberger $\mathrm{M}$, et al. Length and cost of hospital stay of radioiodine ablation in thyroid cancer patients: comparison between preparation with thyroid hormone withdrawal and thyrogen. Eur J Nucl Med Mol Imaging 2008;35:1457-63. doi:10.1007/s00259-008-0754-9.

7. Luster M, Lippi F, Jarzab B, Perros P, Lassmann M, Reiners C, et al. rhTSH-aided radioiodine ablation and treatment of differentiated thyroid carcinoma: a comprehensive review. Endocr Relat Cancer 2005;12:49-64. doi:10.1677/erc.1.00830.

8. Lazar V, Bidart JM, Caillou B, Mahé C, Lacroix L, Filetti S, et al. Expression of the $\mathrm{Na}+/ \mathrm{I}-$ symporter gene in human thyroid tumors: a comparison study with other thyroid-specific genes. J Clin Endocrinol Metab 1999;84:3228-34. doi:10.1210/jc.84.9.3228.

9. Zanotti-Fregonara P, Duron F, Keller I, Khoury A, Devaux JY, Hindié E. Stimulation test in the follow-up of thyroid cancer: plasma rhTSH levels are dependent on body weight, not endogenously stimulated TSH values. Nucl Med Commun 2007;28:257-9. doi:10.1097/MNM.0b013e32804c58c2.

10. Robbins RJ, Tuttle RM, Sonenberg M, Shaha A, Sharaf R, Robbins $\mathrm{H}$, et al. Radioiodine ablation of thyroid remnants after preparation with recombinant human thyrotropin. Thyroid 2001;11:865-9. doi:10.1089/105072501316973127.

11. Zanotti-Fregonara P, Keller I, Rubello D, Calzada-Nocaudie M, Devaux JY, Hindié E. TSH variations may explain some positive 131I therapy scans in patients with negative diagnostic scans. J Endocrinol Invest. In press.

12. Ladenson PW, Braverman LE, Mazzaferri EL, Brucker-Davis F, Cooper DS, Garber JR, et al. Comparison of administration of recombinant human thyrotropin with withdrawal of thyroid hormone for radioactive iodine scanning in patients with thyroid carcinoma. N Engl J Med 1997;337:888-96. doi:10.1056/ NEJM199709253371304.

13. Hindié E, Zanotti-Fregonara P, Keller I, Duron F, Devaux JY, Calzada-Nocaudie $\mathrm{M}$, et al. Bone metastases of differentiated thyroid cancer: impact of early 131I-based detection on outcome. Endocr Relat Cancer 2007;14:799-807. doi:10.1677/ERC-070120.

14. Taïeb D, Jacob T, Zotian E, Mundler O. Lack of efficacy of recombinant human thyrotropin versus thyroid hormone withdrawal for radioiodine therapy imaging in a patient with differentiated thyroid carcinoma lung metastases. Thyroid 2004;14:465-7. doi:10.1089/105072504323150804.

15. Driedger AA, Kotowycz N. Two cases of thyroid carcinoma that were not stimulated by recombinant human thyrotropin. J Clin Endocrinol Metab 2004;89:585-90. doi:10.1210/jc.2003-031650. 
16. Pötzi C, Moameni A, Karanikas G, Preitfellner J, Becherer A, Pirich $\mathrm{C}$, et al. Comparison of iodine uptake in tumour and nontumour tissue under thyroid hormone deprivation and with recombinant human thyrotropin in thyroid cancer patients. Clin Endocrinol (Oxf) 2006;65:519-23. doi:10.1111/j.1365-2265.2006.02626.x.

17. Braga M, Ringel MD, Cooper DS. Sudden enlargement of local recurrent thyroid tumor after recombinant human TSH administration. J Clin Endocrinol Metab 2001;86:5148-51. doi:10.1210/jc.86.11.5148.

18. Zanotti-Fregonara P, Hindié E, Faugeron I, Moretti JL, Ravasi L, Rubello D, et al. Update on the diagnosis and therapy of distant metastases of differentiated thyroid carcinoma. Minerva Endocrinol 2008;33:313-27.

19. Rubino C, de Vathaire F, Dottorini ME, Hall P, Schvartz C, Couette JE, et al. Second primary malignancies in thyroid cancer patients. Br J Cancer 2003;89:1638-44. doi:10.1038/sj.bjc. 6601319.

20. Brown AP, Chen J, Hitchcock YJ, Szabo A, Shrieve DC, Tward JD. The risk of second primary malignancies up to three decades after the treatment of differentiated thyroid cancer. J Clin Endocrinol Metab 2008;93:504-15. doi:10.1210/jc.2007-1154. 